\title{
Introducing Geoscience Students to Numerical Modeling of Volcanic Hazards: The example of Tephra2 on VHub.org
}

\author{
Leah M. Courtland \\ University of South Florida, courtland@mail.usf.edu \\ Charles Connor \\ University of South Florida, cbconnor@usf.edu \\ Laura Connor \\ University of South Florida, Iconnor@usf.edu \\ Costanza Bonadonna \\ University of Geneva, Costanza.Bonadonna@unige.ch
}

Follow this and additional works at: https://digitalcommons.usf.edu/numeracy

Part of the Environmental Indicators and Impact Assessment Commons, Geology Commons, Science and Mathematics Education Commons, and the Volcanology Commons

\section{Recommended Citation}

Courtland, Leah M., Charles Connor, Laura Connor, and Costanza Bonadonna. "Introducing Geoscience Students to Numerical Modeling of Volcanic Hazards: The example of Tephra2 on VHub.org." Numeracy 5, Iss. 2 (2012): Article 6. DOI: http://dx.doi.org/10.5038/1936-4660.5.2.6 


\title{
Introducing Geoscience Students to Numerical Modeling of Volcanic Hazards: The example of Tephra2 on VHub.org
}

\begin{abstract}
The Tephra2 numerical model for tephra fallout from explosive volcanic eruptions is specifically designed to enable students to probe ideas in model literacy, including code validation and verification, the role of simplifying assumptions, and the concepts of uncertainty and forecasting. This numerical model is implemented on the VHub.org website, a venture in cyberinfrastructure that brings together volcanological models and educational materials. The VHub.org resource provides students with the ability to explore and execute sophisticated numerical models like Tephra2. We present a strategy for using this model to introduce university students to key concepts in the use and evaluation of Tephra2 for probabilistic forecasting of volcanic hazards. Through this critical examination students are encouraged to develop a deeper understanding of the applicability and limitations of hazard models. Although the model and applications are intended for use in both introductory and advanced geoscience courses, they could easily be adapted to work in other disciplines, such as astronomy, physics, computational methods, data analysis, or computer science.
\end{abstract}

\section{Keywords}

geoscience, volcanology, numerical model, model literacy, tephra, geologic hazards

\section{Creative Commons License}

\section{(i) (5)}

This work is licensed under a Creative Commons Attribution-Noncommercial 4.0 License

\section{Cover Page Footnote}

Leah Courtland is a PhD candidate at the University of South Florida. She uses geophysics and numerical modeling to study volcanic hazards.

Chuck Connor is a professor in the Department of Geology at the University of South Florida, where he teaches Natural Hazards to general education students, Physical Volcanology to upper-division undergraduates and first-year graduate students, and Potential Fields to advanced graduate students. He is a geophysicist and volcanologist specializing in hazard assessment.

Laura Connor works as a research associate within the Department of Geology at the University of South Florida. Using her degree in Computer Science, she works to promote computer and programming literacy and supports research focused on modeling natural hazards.

Costanza Bonadonna is an associate professor of Geological Risk at the University of Geneva and director of the CERG-C program (www.unige.ch/hazards/). Her research focuses on various aspects of explosive volcanism and is based on the integration of theoretical, modelling and field approaches. 


\section{Introduction}

Modern geoscience research relies on numerical models to act as surrogates for direct observations of geologic processes and to forecast future events. The time and length scales of geologic processes, for example the long time scale of the earthquake cycle or the continental scale of Earth's largest volcanic eruptions, often limit the applicability of small-scale physical experiments and hamper direct observations. It is no surprise then that the U.S. government, for example, spends billions of dollars each year to fund projects related to numerical modeling in the geosciences (Sarewitz and Pielke Jr. 2000). Models exist to simulate natural hazards such as hurricanes, tornadoes, landslides, tsunamis, volcanic plumes, lava flows, lahars, pyroclastic flows, ballistic volcanic projectiles, snow avalanches, flooding, coastal erosion, the spread of nuclear contamination, and more (Schilling 1998; Tinti et al. 1999; Sarewitz et al. 2000; Mastin 2001; Todesco et al. 2002; Pitman et al. 2003; Favalli et al. 2005; Macedonio et al. 2005; Patra et al. 2005; Rongo et al. 2008, Connor et al. 2012). In these and other numerical models, fundamental assumptions are made about complex systems in order to describe them in mathematical terms. Ultimately, hazard models provide people around the world with a basis for defining and describing catastrophic events. Model results are used to direct public policy, guide land use practices, plan mitigation measures, and delineate evacuation zones in areas of high risk. Ultimately, these and other applications require input from community members, government officials, and judiciary bodies, necessitating a basic level of model literacy within the general population.

Given the high stakes, it is essential to understand the uses, strengths, and weaknesses of these quantitative tools. Just as an understanding of the scientific method falls within the realm of quantitative literacy (Miller 2004), so too does the ability to use and interpret the results of numerical models ("model literacy"). Code verification, code validation, the use and understanding of simplifying assumptions (model parsimony), model uncertainty (often termed epistemic uncertainty, see Benjamin and Cornell 1970), and forecasting all must be addressed if individuals are to become numerate with regard to the role of quantitative models in society. Scrutinizing these issues in a classroom setting prepares students for future encounters with numerical models while at the same time exposing them to a wealth of traditional quantitative literacy concepts such as unit conversion, data interpretation, magnitudes, exponential decay, Gaussian functions, and probabilities.

Access to numerical models is an important first step toward developing model literacy. VHub.org, a cyberinfrastructure project focused on volcanological modeling and education, provides one means by which students may achieve access. The term 'cyberinfrastructure' refers to a coordinated research 
environment designed to support progress in science and engineering by integrating advanced computing and information processing services available via the Internet (NSF Cyberinfrastructure Council 2007). The VHub.org project aims to promote the generation and advancement of volcanological theories, education, and risk assessment by providing an environment both technologically and sociologically capable of connecting data, computers, and people. To that end, the VHub.org website ${ }^{1}$ hosts a collection of numerical models that execute on the hub's servers. This structure negates the need for code installation on a personal computer and enhances the availability of modeling tools for the general public (Valentine et al. 2009). Our experience suggests that this cyberinfrastructure can be used to teach students the importance of model verification and validation, to highlight the types of questions that can and cannot be asked of models, and additionally to explore the concept of forecasts in natural hazard assessments.

This paper presents a numerical hazard model we designed to teach fundamental modeling concepts. This model, Tephra2, estimates the dispersion of tephra, fragments of volcanic rock thrown into the air during explosive volcanic eruptions. The Tephra2 student interface implemented on VHub.org is designed to encourage students from a range of disciplines and experience levels to consider issues of model validation, verification, simplifying assumptions, and hazard forecasting in the context of tephra dispersion in the classroom environment. In the following we describe the cyberinfrastructure that makes this possible, briefly describe the tephra dispersion model (Bonadonna et al. 2005; Connor and Connor 2006), and illustrate the use of the student interface. While the focus is on introductory and advanced geology students, the general concepts, as well as exercises utilizing the Tephra 2 model, could be adapted for inclusion in a broader range of courses including for example astronomy, physics, computational methods, data analysis, and computer science.

\section{VHub.org}

The VHub.org website is the result of an international effort to promote the integration of volcanology research and risk mitigation. By providing a link between the fields of education, academic research, and volcano observatories, VHub.org aims to promote geoscience education, to facilitate new and collaborative research in volcanology, and to provide a tool for the mitigation of volcanological hazards around the world (Valentine et al. 2009). In the process of achieving these goals, VHub.org contributors have populated this cyber-

\footnotetext{
${ }^{1}$ www.VHub.org. (This and all other cited VHub links were last accessed 21 June, 2012.)
} 
environment with resources that can be utilized to explore concepts not just of volcanology and natural hazards, but of calculus, numerical modeling, and data visualization.

VHub.org is an open access website that provides a platform from which to execute numerical models without needing to download and install the code, or monopolize the computing resources of one's own computer. Students, academics, those responsible for volcano monitoring, and other interested parties are all able to $\log$ on to the website and run models, called Online Simulation Tools. Each Online Simulation Tool represents a quantitative scientific model that has been installed on VHub.org, tested, and is ready for public use.

In addition to the numerical simulations, VHub.org offers other resources, many of which are helpful in exploring various concepts of quantitative literacy. For example, Spreadsheets Across the Curriculum: The Physical Volcanology Collection can be found among the VHub.org Educational Resources. ${ }^{2}$ These modules use quantitative skills and mathematical problem solving to explore various concepts of physical volcanology. In addition to these modules, various labs, maps, and pre-recorded lecture courses are available. All of these resources have been contributed by VHub.org users and, additionally, all users are welcome to upload their own resources, including lesson plans, homework assignments, models, posters, and other materials which contribute to the advancement of volcanological science, education, and hazard assessment. Although there is no formal peer-review process for contributions to VHub.org, users are encouraged to write informal reviews that include both a rating (between one and five stars) and comments.

\section{Tephra2}

Tephra2 is one of the Online Simulation Tools freely available via the VHub.org website. This program is an open source code that numerically simulates the dispersion of tephra. Tutorials, lessons, manuals, and problem sets relating to the model are available on the website, together with the code and resources to execute computer simulations using the code.

The term 'tephra' describes the fragmented material produced by explosive volcanic eruptions irrespective of particle size, composition, or manner of emplacement. Tephra particles range in size from large boulders to very fine ash. Tephra 2 calculates the erupted mass per unit area $\left(\mathrm{kg} \mathrm{m}^{-2}\right)$ of tephra at specific locations on the ground given a set of eruption conditions specified by the model user. These locations on the ground may be within a few kilometers of the

\footnotetext{
${ }^{2}$ https://VHub.org/resources/521
} 
volcano or up to hundreds of kilometers downwind. The model may be used to simulate a historical eruption or to explore possible scenarios for future eruptions. Various model parameters control the size and style of the simulated eruption. Input parameters (Fig. 1) include the prevailing wind speed and direction at the time of the eruption, the maximum height of the erupting column of tephra, the total amount of tephra erupted, and the range of particle sizes erupted.

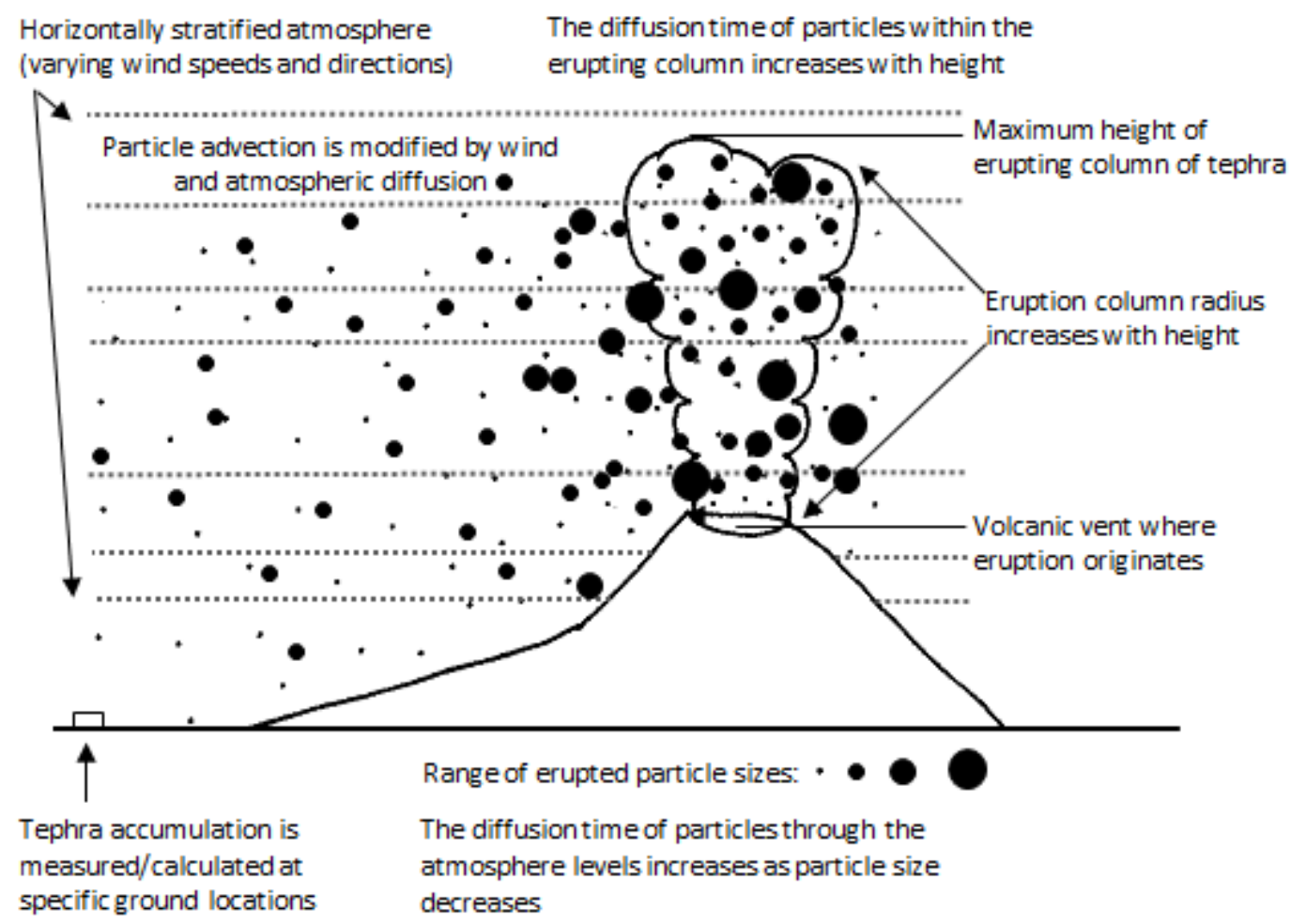

Figure 1. Pictorial description of the key features of the Tephra2 model. The user-supplied grainsize distribution of particles (represented by variously sized dots) is erupted from the vent. Particles experience column diffusion before being released into the atmosphere at an altitude between the vent altitude and the maximum column height. Particles then fall through a horizontally layered atmosphere, with each layer characterized by a unique wind speed and direction. As particles fall, they experience atmospheric diffusion while simultaneously being advected by the wind in each atmospheric layer before settling onto the surface.

The model uses a simplified mass-conservation equation, the advectiondiffusion equation, to describe the transport and diffusion of volcanic particles through the atmosphere. The advection-diffusion equation is of the type given by Suzuki (1983): 
$\frac{\partial C_{j}}{\partial t}+w_{x, l} \frac{\partial C_{j}}{\partial x}+w_{y, l} \frac{\partial C_{j}}{\partial y}-v_{l, j} \frac{\partial C_{j}}{\partial z}=K \frac{\partial^{2} C_{j}}{\partial x^{2}}+K \frac{\partial^{2} C_{j}}{\partial y^{2}}+\Phi$

where $x$ is positive in the mean downwind direction, $y$ is the mean cross-wind direction, and $z$ is vertical; $C_{j}$ is the mass concentration of particles $\left(\mathrm{kg} \mathrm{m}^{-3}\right)$ of a given particle-size class, $j ; w_{x}$ and $w_{y}$ are the $x$ and $y$ components of the wind velocity $\left(\mathrm{m} \mathrm{s}^{-1}\right)$, and vertical wind velocity is assumed to be negligible; $K$ is a horizontal diffusion coefficient for tephra in the atmosphere $\left(\mathrm{m} \mathrm{s}^{-1}\right)$ and is assumed to be constant and isotropic $\left(K=K_{x}=K_{y}\right)$; $v_{i j}$ is the terminal settling velocity $\left(\mathrm{m} \mathrm{s}^{-1}\right)$ for particles of size class, $j$, released at a level in the atmosphere,

$l$; and $\Phi$ is the rate of change in particle concentration $\left(\mathrm{kg} \mathrm{m}^{-3} \mathrm{~s}^{-1}\right)$ at the source with time. The terminal settling velocity, $v_{i j}$, is calculated for each particle size, $j$, released from a height level, $l$, as a function of the particle's Reynolds number, which varies with atmospheric density (Bonadonna et al. 1998). Horizontal wind velocity is allowed to vary as a function of height in the atmosphere and assumed to be constant within a specific atmospheric level and with distance from the vent.

The model calculates an analytical solution of this mass-conservation equation by making a number of simplifying assumptions (Suzuki 1983; Lim et al. 2008). The equation,

$$
f_{l, j}(x, y)=\frac{1}{2 \pi \sigma_{l, j}^{2}} \exp \left(-\frac{\left(x-\bar{x}_{l, j}\right)^{2}+\left(y-\bar{y}_{l, j}\right)^{2}}{2 \sigma_{l, j}^{2}}\right)
$$

is written for a line plume source where $\bar{x}$ and $\bar{y}$ are the coordinates of the center of the bivariate Gaussian distribution and $\sigma_{i, j}^{2}$ is the variance of the distribution, which is controlled by atmospheric and horizontal spreading of the plume (Suzuki 1983).

Using this equation, the program is able to mathematically describe the movement and dispersion of tephra as it leaves the eruption column, falls through a layered atmosphere, and comes to rest on the ground. Model outputs include the mass of tephra accumulation, in units of $\mathrm{kg} \mathrm{m}^{-2}$, and a binned distribution of particle sizes calculated as weight percent of the total mass at specific locations around the erupting volcano. The mass per unit area is often directly used in hazard forecasts, since mass loading by tephra affects infrastructure resilience (Wilson et al. 2012). Small particle sizes directly affect air quality (due to resuspension of particles in the atmosphere); they also increase an area's susceptibility to flooding (tephra can dramatically impact infiltration rates of meteoric water into the ground; Blong 1984). The final footprint of deposited 
tephra predicted by the model is characterized by a Gaussian distribution of erupted material in the crosswind direction and either exponential or power-law thinning in the direction downwind from the vent, depending on varying terminal velocities of the various particles sizes (Pyle 1989; Sparks et al. 1992; Bonadonna et al. 1998; Bonadonna et al. 2005; Lim et al. 2008; Courtland et al. 2012).

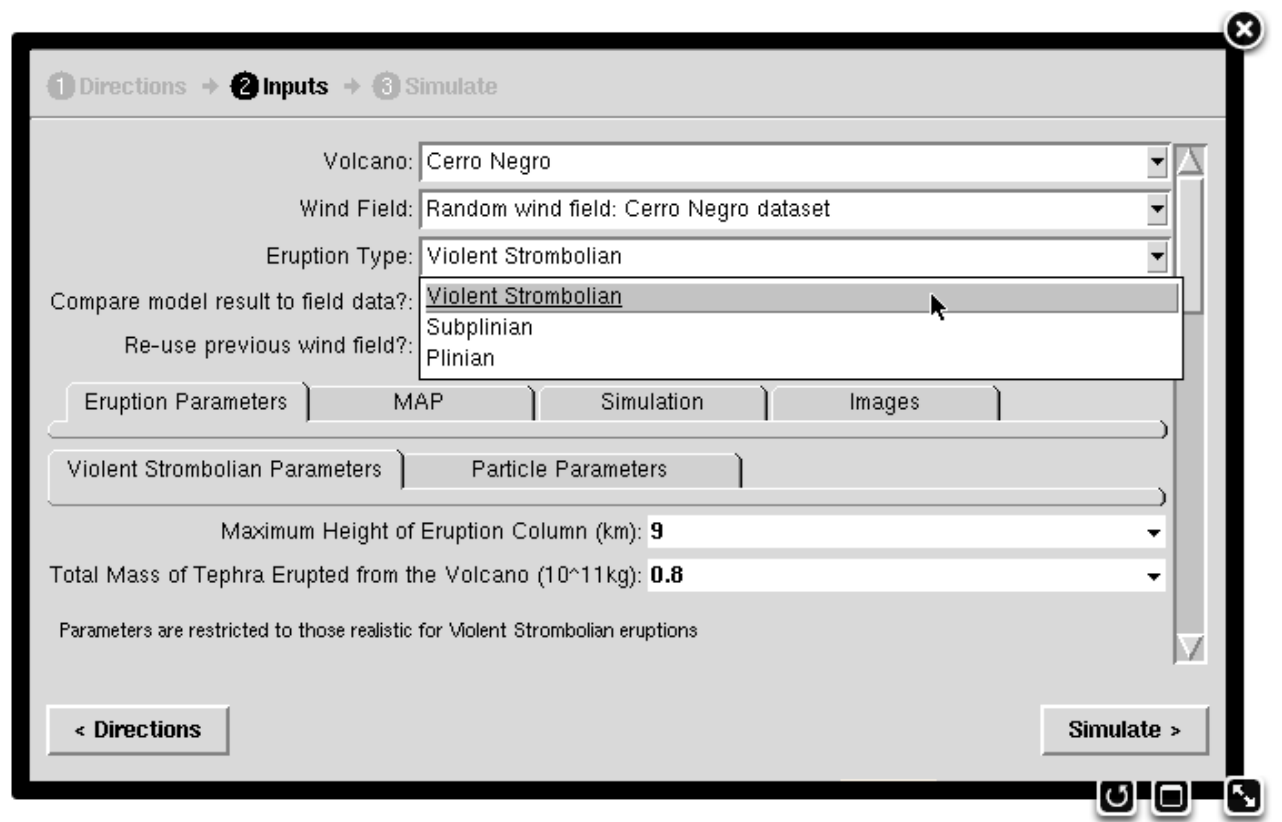

Figure 2. Graphical user interface (GUI) for the student version of Tephra2 implemented on VHub.org. Students select a volcano, a wind profile, and an 'eruption type'. The eruption type determines reasonable values for maximum eruption column height and the total mass of erupted tephra. The Particle Parameters tab contains options for setting the maximum and minimum grain size of erupted particles as well as their density. The Map tab allows a user to define the map boundaries and the spacing of grid locations where tephra accumulation is calculated. The Simulation tab displays options for setting the diffusion coefficient and the height range within the plume from which particles are released. The Information tab contains the values of any eruption parameters recorded at the time of the eruption, a location map, and a photograph of the volcano. See manual for additional explanation of model parameters.

Two graphical user interfaces (GUIs) are available to execute the Tephra2 program on the VHub.org website. The research GUI builds the command sequence that runs the model and has been used by multiple researchers to simulate eruption conditions for specific volcanoes from tephra deposits and to forecast the range of possible future activity (Bonadonna et al. 2005; Connor and Connor 2006; Scollo et al. 2008; Volentik et al. 2009; Volentik et al. 2010; Bias and Bonadonna 2011; Longchamp et al. 2011; Fontijn et al. 2011; Johnston et al. 2012; Biass and Bonadonna, in press). To facilitate model use by users with little or no background knowledge of modeling or volcanology, a student interface 
(Fig. 2) was designed that restricts input parameters to reasonable ranges and provides explanations (including diagrams) of each parameter so that students can more easily run the model and produce realistic output. Background information is supplied for the explosive eruptions of several volcanoes. Details of how to execute both versions are included in the Tephra2 user manual. ${ }^{3}$ Through continued use and fine tuning, it is hoped that the graphical user interface (GUI) will contribute toward an increase in model literacy of its users by facilitating model exploration and encouraging critical thinking about fundamental modeling concepts.

\section{Learning about Numerical Models with Tephra2}

Both graduate and undergraduate students at the University of South Florida have interacted with the Tephra2 code via the VHub.org infrastructure with positive results. Graduate students were asked to compare the model with a simplified analytical solution for tephra fallout that they themselves were required to code. Undergraduate student exercises focused on the relationship between model input and output as well as the ability to read a contour plot, perform unit conversions, and compile the results of multiple model runs into a histogram plot. Both assignments are freely available ${ }^{4}$ on VHub.org. Notably, the undergraduate class, Natural Hazards of the Earth's Surface, attracts an interdisciplinary group of students. The majority of students in this course were able to execute the code on VHub.org, simulate volcanic eruptions, and interpret results of the simulation. Although not quantitatively assessed, this experience upholds the idea that introductory geology courses are an ideal venue for quantitative concepts (e.g.. Wenner et al. 2009; Campbell et al. 2011).

The Tephra2 student interface provides students with the opportunity to directly execute a numerical model, the ability to vary the input parameters directly driving the model, and the experience of questioning and interpreting model results. Specifically, students are encouraged to ask:

- Has the model been verified?

- Has the model been validated?

- How much uncertainty is introduced via the input parameters?

- Are the model assumptions appropriate for the hazard scenario?

\footnotetext{
${ }^{3}$ https://vhub.org/resources/574/download/Tephra2_Manual.pdf

${ }^{4}$ https://vhub.org/resources/1563/download/Natural_Hazards_Tephra_lab.pdf, https://vhub.org/resources/1659/download/tephra_hw.pdf
} 
- What are the meanings of probabilistic statements made using the model?

These fundamental questions transcend discipline and are essential aspects of model literacy. To a certain extent these questions also transcend student experience, although the questions are, of course, addressed in varying detail by introductory, upper-level undergraduate and graduate students. In the following we elaborate on how to use Tephra2 and its student interface to explore these questions and associated concepts.

\section{Has the model been verified?}

Verification exercises scrutinize the solutions generated by varying the model input parameters over some domain of interest in order to identify possible errors or inconsistencies in the code (Oberkampf and Roy 2010). Introducing this concept to students raises awareness of the fact that large computer programs often contain code errors or inconsistencies that are continually discovered and corrected through continued use of the program (Carlson and Minerd 2009).

Students can examine whether the quantitative model is providing reasonable results by comparing the calculated Tephra 2 model result with the known effects of various input parameters. For example, the amount of mass that accumulates on the ground after an eruption should be equal to the amount of material ejected from the volcano (tephra does not melt away as snow does, or infiltrate the ground as rainwater does). This can be checked by integrating the mass accumulated at individual points over the entire grid and comparing the result with the user-supplied value for the total mass ejected from the volcano. The student interface implemented on VHub.org calculates this summation for the student to facilitate an easy comparison. Students are given the opportunity to design an effective verification procedure by manipulating the map size and grid point density to create a tephra fallout surface large enough to capture all of the mass and dense enough to provide a representative sampling of the area about the volcano; conversely they can develop an ineffective verification procedure, for example, if a large fraction of the "erupted" tephra falls outside the map domain they have created or if their grid is too coarse to achieve a precise integration.

Students can make other assessments by examining the effects of various atmospheric wind profiles on the deposit. If there is no wind present during the eruption then, from the advection-diffusion equation, we expect the deposit to form a series of circular isopachs (contour lines of equal mass per unit area or equal deposit thickness). If the wind is blowing, we expect for these isopachs to be offset predominantly in the direction of maximum wind velocity. By selecting a variety of wind profiles while leaving all other parameters constant, students may confirm that Tephra 2 is able to capture the expected general shape for each scenario, examples of which are given in Figure 3. This exercise provides additional evidence that the translation from mathematical to numerical model 
was performed correctly. Similar verification methods were used by code developers, as discussed in the Tephra 2 manual. ${ }^{5}$

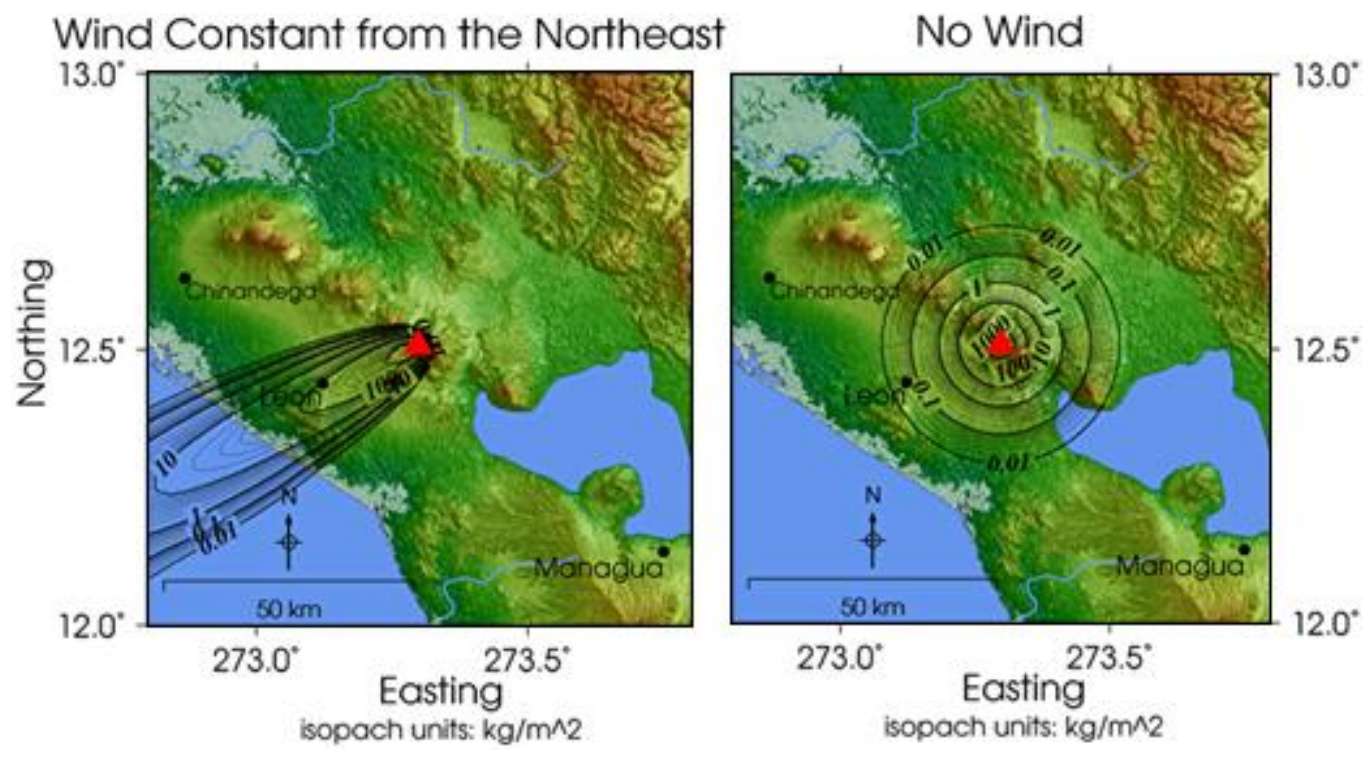

Figure 3. The shape of deposits calculated using two different wind fields with all other parameters held constant. A steady wind field blowing towards the southwest resulted in the plot on the left, while a still atmosphere resulted in the plot on the right. The results agree with those predicted by the advection-diffusion model; in the presence of wind, the advection-diffusion equation predicts an ellipse elongated in the direction of maximum wind velocity and in the absence of wind the equation predicts a circular distribution of material.

\section{Has the model been validated?}

Model validation strives to ensure that a model is an unbiased representation of reality. During the validation process, model predictions are compared to experimental and/or field data. The degree of validation necessary for a given model depends on the purpose and intended use of the model. By engaging in the validation process, students acquire a better understanding of a model's capabilities, limitations, and suitability to address various questions.

The 1992 eruption of Cerro Negro Volcano is one of several eruptions for which field data have been pre-loaded into the Tephra2 student interface. Cerro Negro is a small-volume basaltic cinder cone in Nicaragua. The second largest city in Nicaragua, Léon, is located approximately $20 \mathrm{~km}$ downwind from the volcano and has historically been impacted by tephra fallout from the volcano's

\footnotetext{
${ }^{5}$ https://vhub.org/resources/574/download/Tephra2_Manual.pdf
} 
largest eruptions. The 1992 event was one such eruption, expelling a total mass of $\sim 2 \times 10^{10} \mathrm{~kg}$ of tephra and resulting in more than $1 \mathrm{~cm}$ of tephra fallout $(\sim 10 \mathrm{~kg}$ $\mathrm{m}^{-2}$ ) in Léon (Hill et al. 1998). Tephra thickness data collected at distances 1-13 $\mathrm{km}$ from the volcano (Martin 2004), as well as historically documented eruption parameters, are available to students attempting to model the eruption on VHub.org. With the option 'compare model results to field data' selected, a graph comparing the calculated accumulation of tephra with that observed in the field shortly after the eruption is automatically generated (Fig. 4). This allows students to validate the Tephra2 model against the 1992 Cerro Negro tephra deposit using observed eruption parameters. Validation exercises conducted by the code developers (e.g., Connor and Connor 2006) involved similar procedures and are discussed in the Tephra2 manual. ${ }^{6}$

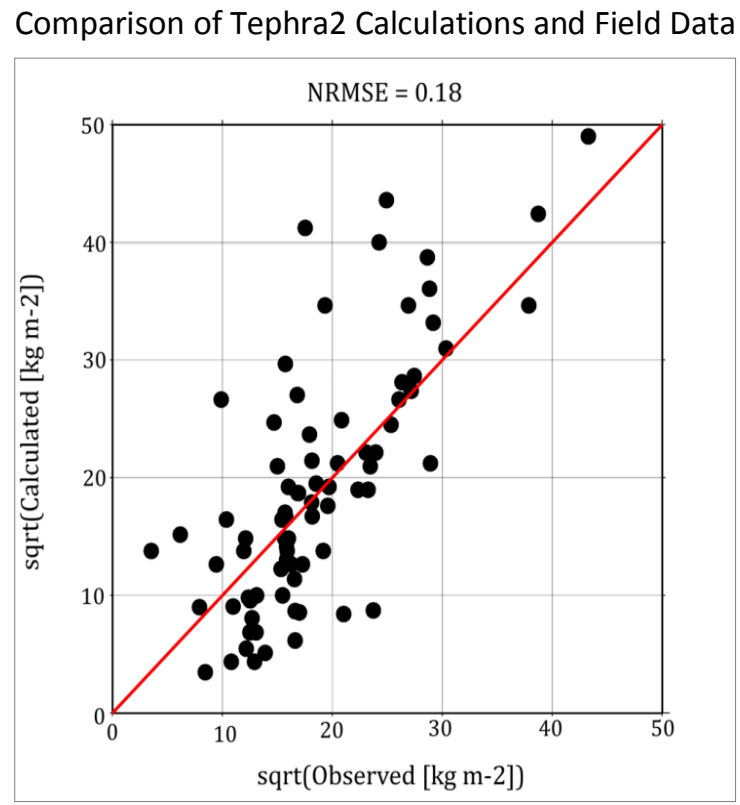

Figure 4. An equiline plot comparing model calculations with directly measured accumulations of tephra (black dots) at locations surrounding Cerro Negro Volcano. The straight red line represents perfect agreement between model calculations and tephra measurements made on site. Notice that most dots do not fall on the 1:1 line. The student interface automatically creates and displays this plot when the option to compare calculated tephra amounts with measured field data is selected. The results are scaled by the square root function for easier viewing. The normalized root mean squared error is shown at the top, useful for comparison of data sets.

\footnotetext{
${ }^{6}$ https://vhub.org/resources/574/download/Tephra2_Manual.pdf
} 


\section{How much uncertainty is introduced via the input parameters?}

A model is only as good as the information that goes into it. Knowing precise values for input parameters such as an exact eruption column height, or a specific grain-size distribution, or the turbulent diffusion coefficient for tephra in the atmosphere, is often impossible. This lack of input parameter precision translates into a loss of accuracy in the model output.

Small changes in the height of the eruption column can have a noticeable effect on the calculated dispersion of tephra. By adjusting this input parameter, students have the ability to recognize the degree to which uncertainty in the model input translates into uncertainty in the thickness of the resultant tephra deposit. Variations in mass loading of tephra of just $100 \mathrm{~kg} \mathrm{~m}^{-2}$ can mean the difference between structural stability and roof collapse in some areas (Wilson et al. 2012). By altering the model input parameters slightly and examining the effect that small variations have on the resultant tephra deposit, students can test the sensitivity of the model.

A more subtle point to make to advanced students is that models often include one or more non-physical parameters. In the case of Tephra2, the diffusion coefficient of the atmosphere is implemented as such a parameter. This parameter is used to take into account various factors which are not explicitly defined elsewhere in the code-factors such as the spreading out of the umbrella cloud and the interaction of tephra particles with the atmosphere. This approach greatly simplifies the model by allowing complex processes that are poorly defined to be described by a single parameter. In practice, models like Tephra2 need to be calibrated in order to determine appropriate values for such nonphysical parameters. Students can calibrate Tephra2 against the eruption of Cerro Negro by setting the physical variables to the values on record for the 1992 eruption. The value of the diffusion coefficient can then be altered by a process of guess and check and the result examined to see how variations in this parameter affect the calculation. Once a satisfactory fit to field data is achieved, this value of the parameter may be used to model other eruptions of similar type. Thus the inclusion of non-physical variables which cannot be uniquely defined prior to an event does not prohibit the application of hazard models, provided that the models have been calibrated.

\section{Are the model assumptions appropriate for the hazard scenario?}

By confronting situations that the program is not well equipped to model, students may realize the importance of questioning a model before applying it to the situation at hand. All numerical models make simplifying assumptions. Decisions 
to include or exclude various parameters or processes are examples of model assumptions. Other assumptions might pertain to the way in which model parameters are characterized. Making simplified mathematical approximations allows scientists to solve quantitative problems more efficiently. This can greatly increase computational speed, an important consideration in hazard assessment. But how valid are the assumptions that go into any quantitative model? By addressing assumptions individually, students have the opportunity to gain an understanding of those situations in which a given model should or should not be applied. The student version of Tephra2 is specifically designed to allow students to explore various model assumptions, including the structure of the atmosphere and the aggregation of tephra particles.

The Tephra2 model approximates the atmosphere as a series of vertically stacked layers which are constant in time and in horizontal space and only vary in the vertical dimension. Within each layer wind speed and direction are constant, but between layers they are allowed to vary. Is this a valid assumption? The real atmosphere, as most students realize, does not behave as abstracted in the Tephra2 model. It is composed of eddies, updrafts, and downdrafts, all of which change position over time. By asking students to brainstorm situations in which this parameterization is justifiable (i.e., when the atmosphere displays little temporal variation and when the eruption column does not disperse over great distances), they will hopefully come to realize that this atmospheric characterization works well for some scenarios and poorly for others.

Particle aggregation is an example of a physical process not explicitly taken into account in the Tephra2 model. Very small particles $(<0.125 \mathrm{~mm})$ form aggregates in the atmosphere (e.g. Carey and Sigurdsson 1982; Gilbert and Lane 1994; Bonadonna et al. 2002; Textor et al. 2004; Costa et al. 2010). This process increases their effective particle size, resulting in dramatically larger particle settling velocities. For eruptions dominated by fine particles, the aggregation process results in one or more secondary thickness maxima in the deposit. After examining a map of the tephra thickness which displays this depositional pattern (Fig. 5), students could attempt to replicate the secondary maxima by altering their input to the Tephra 2 program. However, regardless of the combination of particle sizes and column heights they use, students will not be able to generate a calculation resulting in more than one thickness maxima. This example highlights for students the fact that quantitative models are only valid when applied to the situations that they were designed to investigate.

Model assumptions, including the implementation of model processes and parameters, are justified by model validation exercises. When the numerical simulation of a natural system is capable of providing results that approximate reality to the precision required for a given application, then the assumptions on which the model is based are deemed acceptable. In the case of Tephra2, if the 
model allows users to construct reliable hazard maps, then it has served its purpose. By exploring model assumptions, students discover that models are designed to evaluate the subset of all possible scenarios to which their simplifying assumptions apply. For a more comprehensive list of major assumptions built into the Tephra2 model, see the Tephra2 manual. ${ }^{7}$

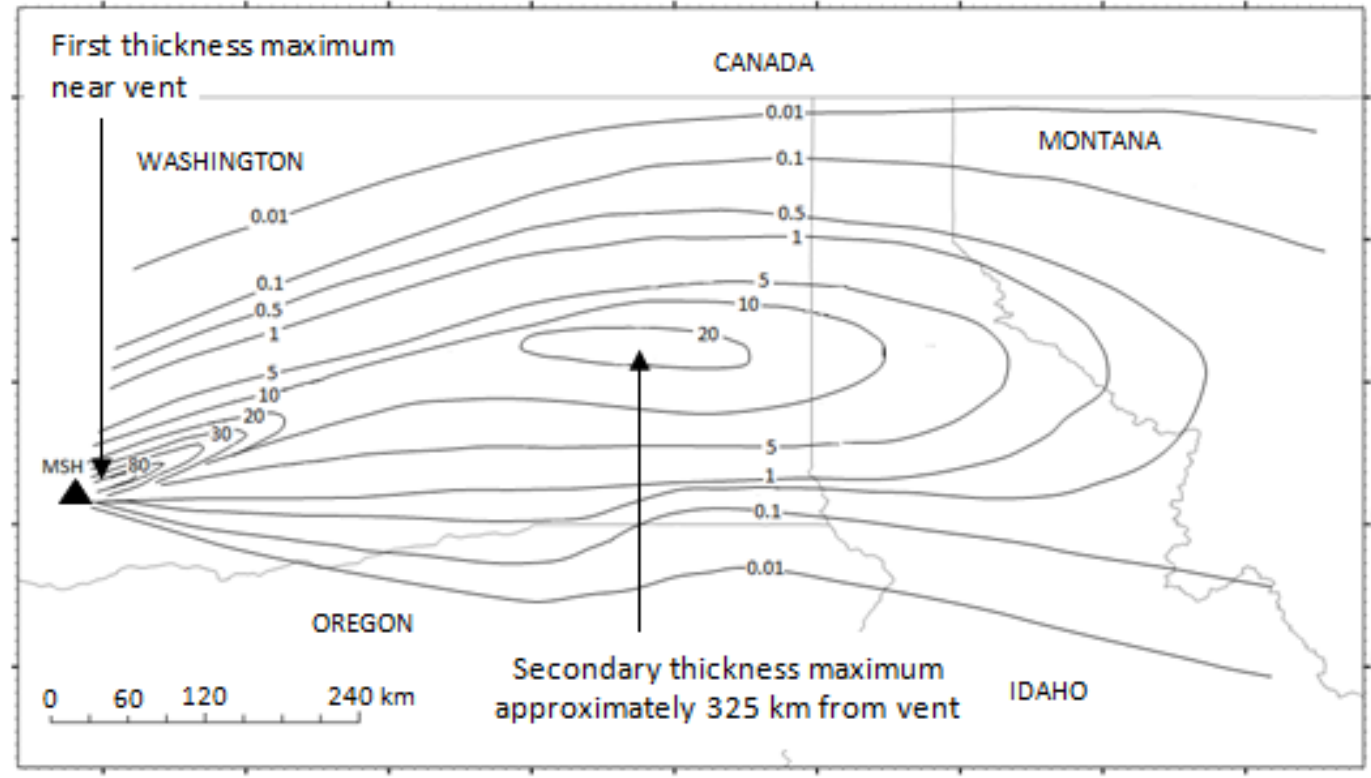

Figure 5. Isomass Map of Sarna-Wojcicki et al. (1981) illustrating secondary maximum resulting from aggregation of fine $(<0.125 \mathrm{~mm})$ particles during the 1980 eruption of Mt St Helens. Isomass contours are in $\mathrm{kg} \mathrm{m}^{-2}$. Ash aggregation is not taken into account in theTephra 2 model. Modified from Durant et al. (2009).

\section{What are the meanings of probabilistic statements made using the model?}

Probabilistic modeling considers a range of input parameters in order to determine the likelihood of multiple outcomes (e.g., Connor et al. 2001; Favalli et al. 2005; Bonadonna 2006; Felpeto et al. 2007; Marzocchi et al. 2008; Connor et al. 2012). These probabilistic models are obtained by running deterministic models hundreds or thousands of times, varying the input parameters for every run such that the entire range of feasible scenarios is sampled. This enables the possible outcomes of a given scenario to be portrayed without endowing unwarranted certainty to the results. The end result of probabilistic modeling is a forecast. By participating in the generation of a probabilistic hazard assessment, students are

\footnotetext{
${ }^{7}$ https://vhub.org/resources/574/download/Tephra2_Manual.pdf
} 
better able to comprehend the meanings of probabilistic statements derived from model use. As students begin to understand how likely various situations are to occur, they simultaneously develop familiarity with probabilistic modeling in general, increasing the likelihood that they will be able to comprehend similar analyses derived from other applications (Connor 2011).

Elements of Tephra2, as well as elements of the VHub.org platform itself, have been specifically designed to conduct probabilistic volcanic hazard assessment as a collaborative exercise. As an example, students could be asked to vary the wind field near Cerro Negro volcano (leaving other parameters constant), and record how frequently tephra fallout in Léon exceeds $1 \mathrm{~cm}$, a value capable of damaging waste sewage treatment plants and other critical facilities (Blong 1984). The Tephra2 student interface allows students to randomly apply one of over 1800 wind profiles derived from REANALYSIS data ${ }^{8}$ for Cerro Negro volcano. Students achieve parallelism by running the simulation multiple times, in the process completing a table similar to Table 1 , and then combining the results of the entire class.

\begin{tabular}{|c|c|c|c|}
\hline Run & $\begin{array}{c}\text { Tephra Accumulation } \\
\qquad\left(\mathrm{kg} / \mathrm{m}^{2}\right)\end{array}$ & $\begin{array}{c}\text { Tephra Thickness } \\
(\mathrm{cm})\end{array}$ & Tephra Accumulation $>1 \mathrm{~cm}$ ? \\
\hline 1 & 7 & 0.7 & No \\
\hline 2 & 0.4 & .04 & No \\
\hline 3 & 20 & 2 & Yes \\
\hline $\begin{array}{l}4 \\
\ldots\end{array}$ & 0 & 0 & No \\
\hline \multicolumn{4}{|c|}{$\begin{array}{l}\text { *Students must convert the accumulation }\left(\mathrm{kg} / \mathrm{m}^{2}\right) \text { to thickness }(\mathrm{cm}) \text { and record } \\
\text { whether it exceeds one } \mathrm{cm} \text {. The input parameters are then adjusted and the exercise } \\
\text { repeated. Conversion of accumulation to thickness is based on a deposit density of } \\
1000 \mathrm{~kg} \mathrm{~m}^{-3} \text {. Once the worksheet has been completed, students bin the data in order } \\
\text { to examine the probability that tephra fallout in Léon will exceed } 1 \mathrm{~cm} \text { given an } \\
\text { eruption of Cerro Negro Volcano. }\end{array}$} \\
\hline
\end{tabular}

Data compilation is facilitated by incorporating the 'Groups' feature of VHub.org into such an assignment. Students can join a virtual VHub.org group set up by the educator for a specific course. Students can record and discuss model results by posting to the group discussion board. Here individuals can access the entire class dataset while participating in the type of collaborative

\footnotetext{
${ }^{8}$ http://www.esrl.noaa.gov/psd/ (accessed 21 June 2012)
} 
exercise that cyberinfrastructure is designed to promote. Further instructions on how to utilize the Group feature in such an exercise can be found in the tool's supporting documents. ${ }^{9}$

\section{Introducing Numerical Hazards Modeling to USF Students}

We have not yet developed quantitative assessments of the impacts of using Tephra2 in the classroom on student understanding of numerical models. Nevertheless, the following outlines our experience introducing this numerical model to students.

Early experimentation with Tephra2 in the classroom primarily involved undergraduate non-majors and focused on using the tool to build various quantitative skills including the ability to read a contour map, convert between units, and plot a histogram. Class size fluctuated around 30 students with STEM and non-STEM majors. Few if any students had previous experience with either numerical modeling or geoscience/volcanology. Mathematical aptitude varied widely.

After attending a class lecture on volcanic ash in which the Tephra2 model was introduced, students were asked to use this model to examine the probability of tephra fallout due to an eruption of Cerro Negro volcano as a homework assignment. ${ }^{10}$ The assignment walked students through setting up accounts with VHub.org and executing the model. The account setup process went smoothly, and students were able to access the model at their leisure and via the computer of their choice. In general, students were able to execute the model itself without incident. Many of the underlying tasks and ideas, however, proved challenging. These difficulties perhaps best reveal the need for specific attention to basic model literacy. Some students initially found the concept of an input variable difficult. We found that many students were not comfortable relating the name of a variable such as 'maximum eruption column height' with the numerical value of the variable (e.g., 7000) and the variable's units (e.g., meters). Many of these students expressed a general lack of confidence in their ability to execute the model properly. These difficulties with the concepts of input variables and code execution likely stem from a lack of experience with modeling in general or with using computers as tools to solve complex problems. Because these difficulties arose, we suspect that the act of generating output using Tephra 2 led to some improvement in students' understanding of numerical models.

\footnotetext{
${ }^{9}$ https://VHub.org/resources/tephra2edu/supportingdocs

${ }^{10} \mathrm{https} / / /$ vhub.org/resources/1563/download/Natural_Hazards_Tephra_lab.pdf
} 
Other major difficulties for students in introductory courses related to interpretation of model output. These difficulties included the ability to equate the lines on the contour plot with tephra thickness, the ability to perform unit conversions, and the ability to bin data and create a histogram plot. While each of these concepts was explained to some degree in class, a large number of students required additional, often one-on-one instruction in order to apply each concept or skill to the task at hand.

Though no formal assessment of student learning was performed, many of the undergraduate students expressed appreciation for the chance to execute a research grade numerical model. When submitting the assignment, one student wrote "Thank you for giving us the opportunity to learn about volcanoes in a more interactive way. I learned a lot from this assignment. Although I may have messed up some of the work, I did the best I could!" while another expressed appreciation that they were able to do "real science."

At the other end of the university spectrum of classroom experience, graduate students were asked to write their own version of a simplified tephra dispersion code as one of nine coding assignments during a 16-week semester. Their code involved the dispersion of tephra released from a single height above the erupting volcano in which all tephra was of uniform particle size, and hence uniform settling velocity, and the wind speed and direction were fixed everywhere and uniform. With these assumptions the analytical solution to equation (1) is greatly simplified. Students who successfully implemented this solution in code found that the resulting tephra deposit is a symmetric bivariate Gaussian function, centered on a maximum that is displaced from the volcano as a function of wind velocity and total particle fall time. By comparison with Tephra2 output, graduate students were able to consider the roles of particle-size variation, variation in particle release height within the eruption column, and other factors that lead to more realistic appearing tephra isopach maps. This exercise, which is available online, ${ }^{11}$ provides an opportunity to discuss model parsimony and complexity based on students' own experiences.

\section{Discussion and Conclusions}

The prevalence of numerical modeling across a broad range of disciplines necessitates a heightened understanding of the concepts of numerical modeling. The abilities to question model applicability and to interpret model results are necessary skills. Students in the geosciences often move on to careers in which they are required to perform hazard assessments, to carry out environmental

${ }^{11}$ https://VHub.org/resources/tephra2/supportingdocs 
impact studies, or to determine the quantities and locations of various natural resources (American Geological Institute 2002). Each of these activities currently involves the application of numerical models. Moreover, if individuals are to participate in current debates over environmental issues relating to everything from nuclear waste disposal to cleanup of superfund sites to regulating carbon dioxide emissions, it is imperative that they understand how numerical models are used to argue all sides of these debates.

Tephra2 as implemented on VHub.org is designed to help students learn to critically assess many aspects of a numerical model. It can be used to help students to understand some basic aspects of numerical models including how to test if a model is a good representation of the real world phenomena it claims to represent, the role of uncertainty in numerical modeling, the benefits, drawbacks, and necessity of simplifying assumptions, and the value of probabilistic (as opposed to deterministic) modeling. Experience using and critically assessing a numerical hazards model is helpful in preparing geoscience students for modern geoscience careers. Moreover, the fundamental skill set involved is applicable to a far broader range of fields embracing not only the traditional science, technology, engineering, and mathematics, but also the profusion of fields that rely on numerical modeling for decision making including, for example, urban planning, finance, public service, military strategy, and healthcare.

\section{Acknowledgements}

This work was supported by a grant from the National Science Foundation (DRL 0940839). The authors are grateful to VHub.org collaborators; Greg Valentine, Marcus Bursik, Eliza Calder, Bruce Pitman, Michael Sheridan, Jose L. Palma (University at Buffalo), Bill Rose and Simon Carn (Michigan Technological University), and Sylvain Charbonnier (University of South Florida). Additionally, four reviewers and editor Len Vacher made extremely helpful comments that improved the manuscript.

\section{References}

American Geological Institute. 2002. Careers in the Geosciences. http://www.agiweb.org/workforce/brochure.html (accessed 21 June 2012)

Benjamin J.R. and C.A. Cornell. 1970. Probability, Statistics and Decision for Civil Engineers. New York; McGraw-Hill.

Biass, S. and C. Bonadonna. 2011. A quantitative uncertainty assessment of eruptive parameters derived from tephra deposits: the example of two large eruptions of Cotopaxi volcano, Ecuador, Bullettin of Volcanology 73(1), 73-90. http://dx.doi.org/10.1007/s00445-010-0404-5 and - Fast GIS-based risk assessment for tephra fallout: the example of Cotopaxi volcano, Ecuador - Part I. Natural Hazards (in press). 
Blong R.J. 1984. Volcanic Hazards. Academic Press Australia.

Bonadonna, C. 2006. Probabilistic modelling of tephra dispersion. In Mader, Coles, Connor, and Connor 2006, 243-259.

, G.G.J. Ernst, and R.S.J. Sparks. 1998. Thickness variations and volume estimates of tephra fall deposits: the importance of particle Reynolds number. Journal of Volcanology and Geothermal Research 81:173-187. http://dx.doi.org/10.1016/S0377-0273(98)00007-9

— G. Macedonio, and R.S.J. Sparks. 2002. Numerical modelling of tephra fallout associated with dome collapses and Vulcanian explosions: application to hazard assessment in Montserrat. In The eruption of Soufrière Hills Volcano, Montserrat, from 1995 to 1999, ed. Druitt, T. H. and B. P. Kokelaar, 517-537. Geological Society of London, Memoirs, 21.

- and B.F. Houghton. 2005. Total grain-size distribution and volume of tephra-fall deposits. Bulletin of Volcanology 67: 441-456. http://dx.doi.org/10.1007/s00445-004-0386-2 , C.B. Connor, B.F. Houghton, L.J Connor, M.Byrne, A. Laing, and T. Hincks. 2005. Probabilistic modeling of tephra dispersion: hazard assessment of a multiphase rhyolitic eruption at Tarawera, New Zealand. Journal of Geophysical Research 110, B03203. http://dx.doi.org/10.1029/2003JB002896

Campbell, K., I. Overeem, and M. Berlin. 2011. Taking it to the streets: the case for modeling in the geosciences undergraduate curriculum. Computers and Geosciences, http://dx.doi.org/10.1016/j.cageo.2011.09.006

Carey, S. and H. Sigurdsson. 1982. Influence of particle aggregation on deposition of distal tephra from the May 18, 1980, eruption of Mount St. Helens volcano. Journal of Geophysical Research 87(B8). 7061-7072. http://dx.doi.org/10.1029/JB087iB08p07061

Carlson, D. and I. Minerd. 2009. Software Design Using C++. Computing \& Information Science Depratment, Saint Vincent College. http://cis.stvincent.edu/html/tutorials/swd/softeng/softeng.html (accessed 21 June 2012)

Connor, C.B. 2011. A Quantitative Literacy View of Natural Disasters and Nuclear Facilities Numeracy 4 (2): Article 2, http://dx.doi.org/10.5038/1936-4660.4.2.2

- B.E. Hill, B. Winfrey, N.M. Franklin, and P.C. LaFemina. 2001. Estimation of volcanic hazards from tephra fallout. Natural Hazards Review 2: 33-42. http://dx.doi.org/10.1061/(ASCE)1527-6988(2001)2:1(33)

— L. Powell, W. Strauch, M. Navarro, O. Urbina, and W.I. Rose. 1993. The 1992 eruption of Cerro Negro, Nicaragua: An example of Plinian-style activity at a small basaltic cinder cone, [abs.]: Eos Transactions, American Geophysical Union 74, 640.

Connor, L.J. and C.B. Connor. 2006. Inversion is the key to dispersion: understanding eruption dynamics by inverting tephra fallout. In Mader, Coles, Connor, and Connor 2006, 231-242.

,,- K. Meliksetian and I. Savov. 2012. Probabilistic approach to modeling lava flow inundation: a lava flow hazard assessment for a nuclear facility in Armenia, Journal of Applied Volcanology 1:3. http://dx.doi.org/10.1186/2191-5040-1-3 
Costa, A., A. Folch, G. Macedonio. 2010. A model for wet aggregation of ash particles in volcanic plumes and clouds: I. Theoretical formulation. Journal of Geophysical Research Vol. 115, B09201. http://dx.doi.org/10.1029/2009JB007175

Courtland, L.M., S.E. Kruse, C.B. Connor, L.J. Connor, I.P. Savov, K.T. Martin. 2012. GPR investigation of tephra fallout, Cerro Negro volcano, Nicaragua: a method for constraining parameters used in tephra sedimentation models. Bulletin of Volcanology forthcoming. http://dx.doi.org/10.1007/s00445-012-0603-3

Durant, A.J., W.I. Rose, A.M. Sarna-Wojcicki, S. Carey, and A.C.M. Volentik. 2009. Hydrometeor-enhanced tephra sedimentation: Constraints from the 18 May 1980 eruption of Mount St. Helens. Journal of Geophysical Research-Solid Earth 114, B03204. http://dx.doi.org/10.1029/2008JB005756

Favalli, M.M.T. Pareschi, A. Neri, and I. Isola. 2005. Forecasting lava flow paths by a stochastic approach. Geophysical Research Letters 32, L03305. http://dx.doi.org/10.1029/2004GL021718

Felpeto, A.,J.Marti, and R. Ortiz. 2007. Automatic GIS-based system for volcanic hazard assessment. Journal of Volcanology and Geothermal Research 166 (2): 106-116. http://dx.doi.org/10.1016/j.jvolgeores.2007.07.008

Fontijn, K., G.G.J. Ernst, C. Bonadonna, M.A. Elburg, E. Mbede, and P. Jacobs. 2011. The $\sim 4$ ka Rungwe Pumice (SW Tanzania): A case of $\sim$ wind-still Plinian fall and no associated pyroclastic flow deposits. Journal of Volcanology and Geothermal Research 73 (9): 1353-1368.

Gilbert, J.S. and S.J. Lane. 1994. The origin of accretionary lapilli. Bulletin of Volcanology v. 56, 398-411. http://dx.doi.org/10.1007/BF00326465

Hill, B.E., C.B. Connor, M.S. Jarzemba, and P.C. LaFemina. 1998. 1995 eruptions of Cerro Negro, Nicaragua and risk assessment for future eruptions. Geological Society of America Bulletin 110:1231-1241. http://dx.doi.org/10.1130/0016-7606(1998)110<1231:EOCNVN>2.3.CO;2

Johnston, E.N., J.C. Phillips, C. Bonadonna, and I.M. Watson. 2012. Reconstructing the tephra dispersal pattern from the Bronze Age eruption of Santorini using an advection-diffusion model. Bulletin of Volcanology, Online First.

King, J.L. and K.L. Kraemer. 1993. Models, facts, and the policy process: The political ecology of estimated truth. Environmental Modeling with GIS, ed. M.F. Goodchild, B.O. Parks, and L.T. Teyart, 353-360. New York: Oxford University Press.

Lim, L.L., W.L. Sweatman, R. McKibben, and C.B. Connor, 2008. Tephra fallout models: The effect of different source shapes on isomass maps. Mathematical Geosciences 40(2): 147-157. http://dx.doi.org/10.1007/s11004-007-9134-4

Longchamp, C., C. Bonadonna, O. Bachmann, and A. Skopelittis. 2011. Characterization of tephra deposits with limited exposure: the example of the two largest explosive eruptions at Nisyros volcano (Greece). Bulletin of Volcanology 73(9): 1337-1352. http://dx.doi.org/10.1007/s00445-011-0469-9

Macedonio, G., A. Costa, A. Longo. 2005. A computer model for volcanic ash fallout and assessment of subsequent hazard. Computers and Geosciences 31(7), 837-845. http://dx.doi.org/10.1016/j.cageo.2005.01.013

Mader, H., S. Cole, C.B. Connor, and L.J. Connor, eds. 2006. Statistics in Volcanology. Special Publications of IAVCEI, 1, Geological Society, London. 
Martin, K. 2004. Limitations of the advection-diffusion equation for modeling tephra fallout: 1992 eruption of Cerro Negro volcano, Nicaragua. M.S. thesis, University of South Florida, Tampa.

Marzocchi, W., L. Sandri, and J. Selva. 2008. BET_EF: a probabilistic tool for long- and short-term eruption forecasting. Bulletin of Volcanology 70(5): 623-632. http://dx.doi.org/10.1007/s00445-007-0157-y

Mastin, L.G. 2001. A simple calculator of ballistic trajectories for blocks ejected during volcanic eruptions. U. S. Geological Survey Open-File Report 01-45, version 1.2, online November 2009.

Miller, J.D. 2004. Public understanding of, and attitudes toward, scientific research: What we know and what we need to know. Public Understanding of Science 13: 273-294. http://dx.doi.org/10.1177/0963662504044908

NSF Cyberinfrastructure Council, National Science Foundation, NSF 07-28, 2007. Cyberinfrastructure Vision for $21^{\text {st }}$ Century Discovery, 6 .

Oberkampf, W.L., and C.J. Roy. 2010. Verification and Validation in Scientific Computing. Cambridge: University Press.

Patra, A., A. Bauer, C.C. Nichita, E.B. Pitman, M.F. Sheridan, M.I. Bursik, B. Rupp, A. Webber, A.J. Stinton, L. Namikawa, and C. Renschler. 2005. Parallel adaptive numerical simulation of dry avalanches over natural terrain. Journal of Volcanology and Geothermal Research 139: 1-21. http://dx.doi.org/10.1016/j.jvolgeores.2004.06.014

Pitman, E.B., C.C. Nichita, A. Patra, A. Bauer, M. Sheridan, and M. Bursik. 2003. Computing granular avalanches and landslides. Physics of Fluids 15 (12): 36383646. http://dx.doi.org/10.1063/1.1614253

Pyle, D.M. 1989. The thickness, volume and grain size of tephra fall deposits. Bulletin of Volcanology 51:1-15. http://dx.doi.org/10.1007/BF01086757

Rongo, R., W. Spataro, D. D'Ambrosio, M.V. Avolio, G.A. Trunfio, and S. Di Gregorio. 2008. Lava flow hazard evaluation through cellular automata and genetic algorithms: an application to Mt Etna volcano. Fundamental Informatics 87(2):247267.

Sarewitz, D. and R.A. Pielke Jr. 2000. Prediction in Science and Policy. In Sarewitz et al. 2000, 11-22.

Sarewitz, D., R.A. Pielke Jr., and R. Byerly Jr. 2000. Prediction: Science, Decision Making, and the Future of Nature. Washington (DC): Island Press.

Sarna-Wojcicki, A.M., S. Shipley, R.B. Waitt Jr., D. Dzurisin, S.H. Wood, P.W. Lipman, and D.R. Mullineaux. 1981. Areal distribution, thickness, mass, volume, and grain size of air-fall ash from the six major eruptions of 1980. In The 1980 Eruptions of Mount St.Helens, Washington, ed. P.W. Lipman and D.R. Mullineaux, 577-600. U. S. Geological Survey Professional Paper 1250, 1980.

Schilling, S. 1998. LAHARZ: GIS programs for automated mapping of lahar-inundation hazard zones. Journal of Volcanology and Geothermal Research 139: 1-21.

Scollo, S., S. Tarantola, C. Bonadonna, M. Coltelli, A. Saltelli. 2008. Sensitivity analysis and uncertainty estimation for tephra dispersal models. Journal of Geophysical Research 113(B06202). 
Sparks, R. S.J., M.I. Bursik, G.J. Ablay, R. M. E. Thomas, and S.N. Carey. 1992. Sedimentation of tephra by volcanic plumes. Part 2: controls on thickness and grainsize variations of tephra fall deposits. Bulletin of Volcanology 54 (8): 685-695. http://dx.doi.org/10.1007/BF00430779

Suzuki, T. 1983. A theoretical model for dispersion of tephra. In Arc Volcanism: Physics and Tectonics, ed. D. Shimozuru and I. Yokoyama, 95-113. Terra Publishing Company.

Textor, C., H.F. Graf, C. Timmreck, and A. Robock. 2004. Emissions from volcanoes In: Emissions of Atmospheric Trace Compounds, ed. C.P. Granier, P. Artaxo, C.E. Reeves, 269-303. Kluwer, Dordrecht.

Tinti, S., E. Bortolucci, A. Armigliato. 1999. Numerical simulation of the landslideinduced tsunami of 1988 on Vulcano Island, Italy. Bulletin of Volcanology 61(1-2): 121-137. http://dx.doi.org/10.1007/s004450050267

Todesco, M., A. Neri, T. Esposito Ongaro, P. Papale, G. Macedonio, R. Santacroce, and A. Longo. 2002. Pyroclastic flow hazard assessment at Vesuvius (Italy) by using numerical modeling. I. Large-scale dynamics. Bulletin of Volcanology 64: 155-177. http://dx.doi.org/10.1007/s00445-001-0189-7

Valentine, G.A., M.D. Jones, M.I. Bursik, E.S. Calder, S.M. Gallo, C. Connor, S.A. Carn, W.I. Rose, D.A. Moore-Russo, C.S. Renschler, B. Pitman, and M.F. Sheridan. 2009. VHub - Cyberinfrastructure for volcano eruption and hazards modeling and simulation. Paper presented at the American Geophysical Union Fall Meeting, San Francisco, CA.

Volentik, A.C.M., C.B. Connor, L.J. Connor, and C. Bonadonna. 2009. Aspects of volcanic hazards assessment for the Bataan nuclear power plant, Luzon Peninsula, Philippines. In:. Volcanic and Tectonic Hazard Assessment for Nuclear Facilities, ed. C.B. Connor, N. Chapman, L. Connor. Cambridge University Press. http://dx.doi.org/10.1017/CBO9780511635380.010

Volentik, A.C.M., C. Bonadonna, C.B. Connor, L.J. Connor, and M. Rosi. 2010. Modeling tephra dispersal in the absence of wind: Insights from the climatic phase of the 2450 BP Plinian eruption of Pululagua volcano (Ecuador). Journal of Volcanology and Geothermal Research 193: 117-136. http://dx.doi.org/10.1016/j.jvolgeores.2010.03.011

Wenner, J.M., E.M. Baer, C.A. Manduca, R. Heather Macdonald, S. Patterson, and S. Mary. 2009. The Case for Infusing Quantitative Literacy into Introductory Geoscience Courses. Numeracy 2(1): Article 4. http://dx.doi.org/10.5038/1936-4660.2.1.4

Wilson, T,J. Cole, D. Johnston, S. Cronin, C. Stewart, and A. Dantas. 2012. Short- and long-term evacuations of people and livestock during a volcanic crisis: lessons from the 1991 eruption of Volcán Hudson, Chile. Journal of Applied Volcanology 1:2. http://dx.doi.org/10.1186/2191-5040-1-2 